\title{
Comparison of the Effectiveness of Existential Group Therapy with Cognitive-Behavioral Group Therapy on Increasing Life Satisfaction among the Methadone Maintenance Patients
}

\author{
Saeed Alami ${ }^{1}$, Saeed Bakhtiarpour ${ }^{2 *}$, Parviz Asgari² ${ }^{(D}$, Naser Seraj Khorrami ${ }^{3}(\mathbb{D}$ \\ ${ }^{1}$ Department of Health Psychology, Khorramshahr-Persian Gulf International Branch, Islamic Azad University, \\ Khorramshahr, Iran \\ 2 Department of Psychology, Ahwaz Branch, Islamic Azad University, Ahvaz, Iran \\ 3 Department of Psychology, Dezful Branch, Islamic Azad University, Dezful, Iran
}

*Corresponding author: Saeed Bakhtiarpour, Department of Psychology, Ahwaz Branch, Islamic Azad University, Ahvaz, Iran Tel: +989017580854

Email:saeedbakhtiarpoor@iauahvaz.ac.ir

Received: 05 Apr. 2020 Accepted: 04 May. 2020 ePublished: 01 Aug. 2020

\begin{abstract}
Background and Objective: Given the success of group psychotherapy as well as drug therapies to improve drug-dependent patients, it is increasingly necessary to compare different interventions to select the most effective way to reduce the problems of methadone maintenance therapists. This study aimed to compare the effectiveness of existential group therapy with cognitive-behavioral group therapy on increasing the life satisfaction of addicted people under methadone maintenance therapy.

Materials and Methods: This semi-experimental study was conducted based on the pretest-posttest method with a control group. The study population included addicted males who underwent methadone maintenance treatment at Qazvin Addiction Treatment and Injury Clinics in 2019, Qazvin, Iran. The participants $(\mathrm{n}=90)$ were randomly selected and divided into experimental (existential and cognitive-behavioral therapy) and control groups. Subsequently, the experimental groups participated in 10 sessions of 120-min per week. The data were analyzed in SPSS software (version 22) through a repeated-measures ANOVA.

Results: The results showed the improvement of life satisfaction in the existential and cognitivebehavioral therapy groups $(\mathrm{P}<0.001)$; however, the control group showed no significant difference in pretest, posttest, and follow-up. Furthermore, the results indicated no significant difference between cognitive-behavioral and existential therapy groups in terms of life satisfaction $(P>0.05)$.

Conclusion: It can be concluded that both cognitive-behavioral and existential therapies are effective in increasing the life satisfaction of addicted patients under methadone maintenance therapy; however, no significant difference was observed between the two experimental groups regarding the increasing level of satisfaction.

Keywords: Cognition, Cognitive behavioral therapy, Methadone, Psychotherapy
\end{abstract}

\section{Background}

Addiction is considered a psychiatric disorder with biological, psychological, and social dimensions in which the individual loses control over drug use and continues to use the drug due to its harmful effects [1]. Opioid addiction is a chronic illness that is often associated with another psychiatric illness. Mood disorders and, above all, depression are among the most common first axis disorders associated with addiction [2]. According to the revised fourth version of the Statistical Diagnostic Guidelines for Mental Disorders, the characteristics of the depressive mood disorder include sadness, low selfconfidence, and a lack of interest in any type of daily activity and enjoyment. Depression leads to a significant disability of the individual in the field of personal and social life, as well as occupational status that affects one's daily functioning, such as eating, sleeping, and health [3].

Methadone maintenance therapy was invented in 1964 to reduce the harm of drug abuse, and its inventors argue that taking high doses of methadone will reduce the tendency to use the substance and prevent the euphoria from consuming it [4]. Methadone maintenance treatment makes it possible for the patient not to use illegal substances and virtually eliminates the need for injections. However, regular and longterm use of methadone prevents the recurrence of illicit use [5]. Furthermore, drug therapy generally improves the patient's mental and physical condition. This treatment is an important way to treat opioid dependence in many parts of the 
world [6]. In this way, the addict is treated with methadone for many years and sometimes even for the rest of one's life. Due to a decrease in temptation, the patient can use it for constructive activities rather than wasting their energy, time, and effort in providing the materials they need. Although this may not lead to completing the cessation of drug use, it will improve the social functioning of the addicts [7-10].

Existential group therapy is considered one of the psychological interventions used in group therapy [11]. It focuses on free will, autonomy, and the search for meaning. This treatment is often focused on the individual, not the symptoms [12]. This approach emphasizes one's capacity to make reasonable choices and maximize one's ability [13]. Moreover, this therapeutic approach seeks to find meaning in life. A sense of purpose in life has a positive relationship with psychological factors that leads to adaptation, life satisfaction, and a good psychological feeling [14]. The studies reported that existential group therapy had effects on the improvement of anxiety [15], spiritual health [16], and mental disorder treatment among the addicts [17]. The group therapy with a cognitive-behavioral approach is considered another psychological intervention that is used for the treatment as a group. The cognitive approaches mainly aim to change addictive behaviors through changes in incorrect cognitions, such as dysfunctional behavior-preserving beliefs [18] or the improvement of positive cognitions, including self-efficacy or motivation to change behavior [19]. This treatment aims to help people identify their dysfunctional cognitions and replace them with effective ones, and subsequently, cope with the unpleasant events, which may occur in their lives [20]. What happens in this treatment is not a change of thought but an attempt to change the thinking model of people. The therapists try to speed up the treatment session by prescribing a set of homework and home environments as they work on the addicts' thoughts [21].

The previously conducted studies reported the effect of group cognitive-behavioral therapy on the addicts. These include the effects of group cognitive-behavioral therapy on the improvement of anxiety [22], as well as alcohol dependence reduction among alcoholics and addicts [23]. Bador and Kerekes [24] found that cognitive-behavioral group therapy reduced depression and anxiety, increased self-esteem, and decreased hopelessness in substance abusers, which led to greater selfesteem before treatment. Somehow, their ability was evaluated to deal with more positive issues and problems resulting in the improvement of selfesteem and depression reduction in their lives. Can
Gür and Okanli [25] investigated the impact of cognitive-behavioral therapy on depression, anxiety, and self-efficacy in people with alcohol abuse in Turkey. They found that the intervention based on cognitive-behavioral therapy was effective in reducing depression and anxiety and increasing their self-efficacy.

Attention should be paid to non-pharmacological and group therapies based on psychological approaches, such as existential and cognitivebehavioral group therapy, increasingly to the addicts. The findings of such studies can provide health care professionals with valuable information to enhance the effectiveness of psychological treatment for the addicts.

\section{Objectives}

This study aimed to compare the effect of existential with cognitive-behavioral group therapies on increasing the life satisfaction of the patients who underwent methadone maintenance therapy in Qazvin province, Iran.

\section{Materials and Methods}

This quasi-experimental study was conducted based on a pretest-posttest design with a control group. The study population consisted of 167 male addicts who referred to Qazvin Addiction Abuse and Injury Reduction Clinics in 2019, Qazvin, Iran, for methadone maintenance treatment. In total, 90 cases were diagnosed with depression and randomly divided into three groups of existential therapy, cognitive-behavioral therapy, and control according to the inclusion and exclusion criteria, as well as the psychiatric clinic interview of the Addiction Treatment Center. The criterion for sample selection was based on effect size, alpha, and test power of $0.25,0.05$, and 0.80 in three groups, respectively. It should be mentioned that the minimum number of samples to achieve the desired power was estimated at 30 cases in each group that was a total of 90 individuals.

Regarding the ethical considerations, the participants were informed of the voluntary nature of the study; moreover, written informed consent was obtained from them. In addition, the research procedures, objectives, and regulations were explained to them before the study. Furthermore, the attitude and beliefs of the people were respected, and they were allowed to leave the study at any stage. Following that, the control group could receive the intervention of the experimental group at the same therapeutic sessions upon completion of the project if they were interested. All documents, questionnaires, and records were kept confidential. 
A total of 90 patients were randomly selected from the eligible volunteers and divided into two experimental and one control groups of 30 people per group. The experimental groups (existential and cognitive-behavioral therapy) participated in 10 sessions of 120 min per week (2.5 months) in the counseling center. In other words, the existential and cognitive-behavioral group therapy received 10 sessions of group counseling and therapy during the implementation process. On the other hand, the control group received no intervention.

It is worth noting that one psychiatrist supervised the research procedure at the relevant center. The inclusion criteria were: 1) consumption of methadone for at least one year, 2) age range from 20 to 50 years, 3) male gender, 4) minimum education level of diploma, and 5) lack of psychiatric disorders according to the clinical interview. On the other hand, the cases who were consuming psychiatric medications and receiving other psychological treatment concurrently with the present study along with those who were absent more than two sessions were excluded from the study.

\section{Satisfaction with Life Scale}

The 5-item Satisfaction with Life Scale (SWLS) was designed to assess the overall judgment of life satisfaction by Diner et al. in 1985. The items are rated on a 7 -point Likert scale (strongly disagree $=1$ ), (disagree $=2)$, (somewhat disagree $=3$ ), (neither agree nor disagree $=4),($ somewhat agree $=5), \quad($ agree $=6)$, and (strongly agree $=7$ ) with the high scores indicating more life satisfaction. Diener et al. [26] estimated the validity of the SWLS using Cronbach's alpha and the test-retest method at 0.83 and 0.69 , respectively. Furthermore, the validity and reliability of this survey were determined at 0.79 and 0.87 , respectively. According to the results of a study conducted by Maroufizadeh et.al [27], the confirmatory factor analysis indicated that a singlefactor model provided a good fit to the data. The

\begin{tabular}{|c|c|}
\hline Session & Content of sessions in brief \\
\hline 1 & $\begin{array}{l}\text { Noting current complaints, getting brief knowledge about the patient's history of the disorder, pharmacotherapy, and } \\
\text { psychotherapy (if any), introducing basic route for Exp, and assessing the suitability of the patient. }\end{array}$ \\
\hline 2 & $\begin{array}{l}\text { Letting the patient give more details of complaints, trying to cover how authentic is patient's life and which obstacles are } \\
\text { working against authenticity, trying to cover which aspects of the patient's life are already close to authenticity. }\end{array}$ \\
\hline 3 & $\begin{array}{l}\text { Structuring the therapeutic dialogue on a phenomenological basis, exploring intangible statements, and directing the patient } \\
\text { to embody his/her speech, demonstrating how apart or close the patient is from or to authenticity in certain fields. }\end{array}$ \\
\hline 4 & $\begin{array}{l}\text { Improving the phenomenological dialogue, improving the embodiment of patient's statements, assessing the patient's stance } \\
\text { toward self-relatedness, directing the patient to express him/herself including physical, relational, and spiritual fields of living. }\end{array}$ \\
\hline 5 & $\begin{array}{l}\text { Improving the phenomenological dialogue, exploring curbs resulting from avoiding embodiment, exploring the patient's } \\
\text { stance toward responsibility and choices of life. }\end{array}$ \\
\hline 6 & $\begin{array}{l}\text { Improving the phenomenological dialogue trying to receive feedbacks concerning patient's certain patterns interfering with } \\
\text { functionality, exploring curbs resulting from avoiding responsibility, directing the patient to negotiate about taking the } \\
\text { responsibility of his/her choices. }\end{array}$ \\
\hline 7 & $\begin{array}{l}\text { Improving the phenomenological dialogue inviting the patient to give feedback about his/her patterns interfering with } \\
\text { functionality, exploring curbs resulting from avoiding responsibility and freedom, directing the patient to negotiate about } \\
\text { taking the responsibility of predictable and unpredictable outcomes of his/her choices. }\end{array}$ \\
\hline 8 & $\begin{array}{l}\text { Improving the phenomenological dialogue inviting the patient to give feedback about his/her feelings about the sessions and } \\
\text { the therapist, exploring strengths of the patients that might have been gained through an enhanced sense of responsibility, } \\
\text { inviting the patient to negotiate about his/her fears concerning freedom. }\end{array}$ \\
\hline
\end{tabular}

Table 2. Cognitive-behavioral group therapy sessions

\begin{tabular}{|c|c|}
\hline Session & Content of sessions in brief \\
\hline 1 & $\begin{array}{l}\text { Noting current complaints, getting brief knowledge about the patient's history of the disorder, pharmacotherapy, and } \\
\text { psychotherapy (if any), showing some cognitive contradictions, setting appropriate and available targets, proposing treatment } \\
\text { rationale for the agenda. }\end{array}$ \\
\hline 2 & $\begin{array}{l}\text { Discussing available cognitive contradictions and showing some more, mentioning the term "automatic thoughts" and } \\
\text { deriving them from existing contradictions, demonstrating possible initiating, triggering, and maintaining factors, and setting } \\
\text { homework(s). }\end{array}$ \\
\hline 3 & $\begin{array}{l}\text { Evaluation of homework(s) exploring more automatic thoughts and evaluating alternative thoughts against them, elaborating } \\
\text { triggering and maintaining factors, and setting new homework(s). }\end{array}$ \\
\hline 4 & $\begin{array}{l}\text { Checking the homework(s), testing certain automatic thoughts and elaborating more, evaluating alternative thoughts, } \\
\text { retracing triggering, and maintaining factors, and setting new homework(s). }\end{array}$ \\
\hline 5 & $\begin{array}{l}\text { Checking the homework(s), testing and evaluating more (new, if explored any) automatic thoughts, elaborating and retracing } \\
\text { initiating factors, mentioning the term "intermediary beliefs" and deriving some of them from outcomes until then, and } \\
\text { setting new homework(s). }\end{array}$ \\
\hline 6 & $\begin{array}{l}\text { Checking the homework(s), elaborating and testing intermediary beliefs, evaluating original and current targets, and setting } \\
\text { new homework(s). }\end{array}$ \\
\hline 7 & $\begin{array}{l}\text { Checking the homework(s), testing more (new, if explored any) intermediary beliefs retracing initiating factors, and setting } \\
\text { new homework(s). }\end{array}$ \\
\hline 8 & $\begin{array}{l}\text { Checking the homework(s), overall assessment of alternative automatic thoughts and intermediary beliefs, overall assessment } \\
\text { of original and current targets, and setting new (monthly) homework(s). }\end{array}$ \\
\hline
\end{tabular}


Cronbach's alpha coefficient of the SWLS was obtained at 0.88 .

The data were analyzed in SPSS software (version 23) through repeated measures ANOVA.

\section{Results}

The mean $\pm S D$ ages of the participants (age range: 20-35) were $25.58 \pm 7.45,26.58 \pm 7.79$, and $27.5 \pm 7.84$ years in the existential, cognitive-behavioral, and control groups, respectively.

The results of Table 3 indicate a significant increase in the scores of both experimental groups, compared to the control group in terms of life satisfaction at the posttest and follow-up. The results indicated that all three groups had normal distribution and homogeneity of variances $(\mathrm{P}<0.05)$.
In addition, the results of the Muachley spherical test $(\chi 2=2.11, \mathrm{P}<0.10)$ and $\mathrm{M}$ box test $(\mathrm{F}=2.09$, $\mathrm{P}<0.13)$ indicated the homogeneity of variancecovariance matrices and within-subjects variance equality.

Table 4 indicates the significant difference among the three groups of existential, cognitive-behavioral, and control in terms of life satisfaction $(\mathrm{P}<0.001)$.

Table 5 tabulates the significant difference between at least two stages in the three experimental and control groups regarding life satisfaction measurement.

As can be seen in Table 6 , the results of the post hoc test indicate no significant difference between cognitive-behavioral and existential therapy groups in terms of life satisfaction.

Table 3. Mean \pm SD of depression scores in the pretest, posttest, and follow-up in three groups

\begin{tabular}{|c|c|c|c|c|}
\hline Group & $\begin{array}{c}\text { Pretest } \\
\text { Mean } \pm \text { SD }\end{array}$ & $\begin{array}{c}\text { Posttest } \\
\text { Mean } \pm \text { SD }\end{array}$ & $\begin{array}{l}\text { Follow-up } \\
\text { Mean+SD }\end{array}$ & P-value \\
\hline Control & $12.1 \pm 1.2$ & $12.1 \pm 2.9$ & $12.2 \pm 2.9$ & 0.76 \\
\hline Cognitive-behavioral therapy & $12.1 \pm 1.3$ & $20.5 \pm 1.1$ & $21.1 \pm 1.5$ & 0.001 \\
\hline Existential therapy & $11.8 \pm 1.8$ & $16.9 \pm 3.1$ & $16.9 \pm 2.9$ & 0.001 \\
\hline
\end{tabular}

Table 4. Results of mixed analysis of variance with repeated measures in three groups in three stages

\begin{tabular}{|c|c|c|c|c|c|c|c|}
\hline & \multicolumn{2}{|c|}{ Source of Changes } & Total squares & Degree of freedom & Mean squares & $F$ & Effect size \\
\hline \multirow{3}{*}{$\begin{array}{l}\text { Life } \\
\text { satisfaction }\end{array}$} & Intragroup & Stages & 3768.57 & 2 & 1884.28 & 63.68 & 0.79 \\
\hline & Intergroup & Intervention & 2176.46 & 2 & 1088.23 & 136.63 & 0.88 \\
\hline & Interaction & Stages $\times$ intervention & 1549.87 & 4 & 387.46 & 48.64 & 0.68 \\
\hline
\end{tabular}

Table 5. Comparison of the simple intra-group effect of three groups on life satisfaction

\begin{tabular}{|c|c|c|c|c|c|c|c|}
\hline Groups & Variable & Effect source & Total squares & Degree of freedom & Mean squares & $\mathrm{F}$ & H square \\
\hline \multirow[b]{2}{*}{ Existential therapy } & Life & Stage & 63.28 & 1 & 63.28 & \multirow[b]{2}{*}{4.81} & \multirow[b]{2}{*}{0.24} \\
\hline & satisfaction & Error & 177.09 & 14 & 15.49 & & \\
\hline \multirow{2}{*}{$\begin{array}{l}\text { Cognitive- } \\
\text { behavioral therapy }\end{array}$} & Life & Stage & 397.55 & 1 & 397.55 & \multirow{2}{*}{16.84} & \multirow{2}{*}{0.53} \\
\hline & satisfaction & Error & 344.12 & 14 & 26.80 & & \\
\hline \multirow{2}{*}{ Control } & Life & Stage & 0.76 & 1 & 0.74 & \multirow{2}{*}{1.11} & \multirow{2}{*}{0.09} \\
\hline & satisfaction & Error & 22.51 & 14 & 1.34 & & \\
\hline
\end{tabular}

${ }^{*} \mathrm{P}<0.05,{ }^{* *} \mathrm{P}<0.01$

Table 6. Results of the Tukey post hoc test to compare two experimental and control groups

\begin{tabular}{lcccc}
\hline Variable & Group & Group & Mean difference & Standard error \\
\hline \multirow{2}{*}{ Life satisfaction } & Cognitive-Behavioral & Existential & 2.07 & 2.86 \\
& Existential & Control & $-14.41^{* *}$ & 2.86 \\
\hline$* * P<01, * P<0.05$ & Control & $-8.27^{*}$ & 2.86 \\
\hline
\end{tabular}

**P $<0.01, * P<0.05$

\section{Discussion}

The results indicated that existential group therapy had an impact on the life satisfaction of addicts under methadone maintenance therapy. This finding was in line with the results of a study conducted by Kajbaf et al. [28] regarding the effect of spiritual and existential group therapy on depression, anxiety, and death rates among the students. The impact of existential group therapy on the enhancement of life satisfaction indicates that existential group therapy seeks to inform the individual about the duties and responsibilities of life focusing on the freedom and responsibility of individuals that lead to stop worrying.

Moreover, logotherapy removes the symptoms of the disease and enables the person to cope with the essential difficulties of life and achieve well-being, as well as mental health leading to increased life satisfaction in individuals among the addicts [17]. Attendance in such existential group therapy sessions enhances the purpose and values of life; moreover, the interaction with one's peers increase 
individual responsibility. Furthermore, choosing a purpose and finding meaning in life can help failed and injured people overcome their depression and accept responsibility for their lives [14].

The results indicated that cognitive-behavioral group therapy had an impact on the life satisfaction of addicts under methadone maintenance therapy. This finding was in line with that of a study performed by Khaledian et al. [29] investigating the effectiveness of cognitive-behavioral group therapy on increasing life satisfaction among the addicts. Cognitive-behavioral therapy for depression emphasizes the negative tendency in the information process due to the distortions of the self, environment, and future, which are associated with the individual's incompatible beliefs that are evoked by the individual. The cognitive-behavioral techniques reinforce the planning to achieve the goals and reduce depression through challenging negative thoughts [19].

The cognitive-behavioral techniques reinforce plan development to achieve goals and reduce depression by challenging negative thoughts. In explaining these findings, it can be said that with the change in behavior of these people, new experiences enter their lives to the extent that the person feels satisfied after completing his treatment [11]. Due to the importance of cognitive-behavioral therapy, it leads to behavior and addiction reconstruction and reduces negative attitudes.

Therefore, this treatment approach is successful in reducing psychological problems, such as depression, in addicts and increasing life satisfaction since this approach is based on the theory of social learning, which can be the basis for appropriate behaviors in addicts [12].

Among the limitations of this study, one can name the self-reports of the study instruments. Another significant limitation of this study was that the control group had no regular counseling sessions to eliminate the expected effect of group therapy due to time and facilities limitations. It is suggested that various techniques of cognitive-behavioral therapy (i.e., avoiding stimulus situations or modifying responses to such stimuli and giving new responses to them) be considered in the rehabilitation centers.

\section{Conclusions}

Both cognitive-behavioral therapy and existential therapy are effective in increasing the life satisfaction of those addicted to methadone maintenance. However, there was no significant difference between the two groups in terms of life satisfaction.

\section{Compliance with ethical guidelines}

Regarding the ethical considerations, the participants were informed about the research objectives and procedures.
Moreover, informed consent was obtained from the subjects, and they were assured of the confidentiality of their information. They also had the right to withdraw from the study if desired. Furthermore, they were informed that they would be provided with the results of the study.

This study was extracted from a Ph.D. thesis of the first author and approved by the Ethics Committee of Khorramshahr-Persian Gulf International Branch, Islamic Azad University. Khorramshahr, Iran (IR.IAU.AHVAZ.REC.1398.015).

\section{Acknowledgments}

The authors would like to thank all participants who greatly contributed to conducting the study.

\section{Authors' contributions}

Conceptualization [Saeed Alami]; Methodology [Saeed Bakhtiarpour]; Investigation [Naser Seraj Khorrami]; WritingOriginal Draft [Parviz Asgari]; Writing-Review and Editing, Author names [all authors]; Funding Acquisition, [all authors]; Resources, [all authors]; Supervision, [Saeed Bakhtiarpour].

\section{Funding/Support}

This study received no specific grants from funding agencies in the public, commercial, or not-for-profit sectors.

\section{Conflicts of Interest}

The authors declare that they have no conflict of interests.

\section{References}

1. Murthy P, Mahadevan J, Chand PK. Treatment of substance use disorders with co-occurring severe mental health disorders. Current Opinion in Psychiatry. 2019; 32(4):293-9. [DOI:10.1097/YCO.0000000000000510] [PMID]

2. Roos CR, Bowen S, Witkiewitz K. Baseline patterns of substance use disorder severity and depression and anxiety symptoms moderate the efficacy of mindfulness-based relapse prevention. Journal of Consulting and Clinical Psychology. 2017; 85(11):1041-51. [DOI:10.1037/ccp0 000249] [PMID] [PMCID]

3. Dunlop K, Hanlon CA, Downar J. Noninvasive brain stimulation treatments for addiction and major depression. Annals of the New York Academy of Sciences. 2017; 1394(1):31-54. [DOI:10.1111/nyas.12985] [PMID] [PMCID]

4. Crapanzano KA, Hammarlund R, Ahmad B, Hunsinger N Kullar R. The association between perceived stigma and substance use disorder treatment outcomes: a review. Substance Abuse and Rehabilitation. 2019; 10(2):1-12. [DOI:10.2147/SAR.S183252] [PMID] [PMCID]

5. Wang $M$, Shen J, Liu X, Deng Y, Li J, Finch E, et al. Reliability and validity of the treatment outcome profile among patients attending methadone maintenance treatment programs in Kunming, China. Journal of Substance Abuse Treatment. 2017; 77(1):89-94. [DOI:10.1016/j.jsat. 2017.03.004] [PMID]

6. Martinez-Luna N, Rodriguez-Cintas L, Esojo A, PalmaAlvarez RF, Robles-Martinez M, Grau-Lopez L, et al. Harm reduction program use, psychopathology and medical severity in patients with methadone maintenance treatment. Adicciones. 2018; 30(3):197-207. [DOI:10.20882/ adicciones.897] [PMID]

7. Peles E, Sason A, Malik E, Schreiber S, Adelson M. Characteristics and outcome of methadone maintenance treatment (MMT) patients with depression. European Psychiatry. 2016; 33(S1):S311-2. [DOI:10.1016/j.eurpsy. 2016.01.1065]

8. Werb D, Kamarulzaman A, Meacham MC, Rafful C, Fischer B, Strathdee SA, et al. The effectiveness of compulsory drug treatment: a systematic review. International Journal of Drug Policy. 2016; 28(2):1-9. [DOI:10.1016/j.drugpo.2015.12. 005] [PMID] [PMCID]

9. Roberts NP, Roberts PA, Jones N, Bisson Jl. Psychological interventions for post-traumatic stress disorder and comorbid substance use disorder: A systematic review and 
meta-analysis. Clinical Psychology Review. 2015; 38(1):2538. [DOI:10.1016/j.cpr.2015.02.007] [PMID]

10. Pinedo M, Zemore S, Rogers S. Understanding barriers to specialty substance abuse treatment among Latinos. Journal of Substance Abuse Treatment. 2018; 94(1):1-8. [DOI:10.1016/j.jsat.2018.08.004] [PMID] [PMCID]

11. Coco GL, Melchiori F, Oieni V, Infurna MR, Strauss B, Schwartze D, et al. Group treatment for substance use disorder in adults: a systematic review and meta-analysis of randomized-controlled trials. Journal of Substance Abuse Treatment. 2019; 99(4):104-16. [DOI:10.1016/j.jsat.2019. 01.016] [PMID]

12. Vos J, Craig M, Cooper M. Existential therapies: a metaanalysis of their effects on psychological outcomes. Journal of Consulting and Clinical Psychology. 2015; 83(1):115-28. [DOI:10.1037/a0037167] [PMID]

13. Thir M, Batthyány A. The state of empirical research on logotherapy and existential analysis. Logotherapy and Existential Analysis. 2016; 4(3):53-74. [DOI:10.1007/978-3319-29424-7_7]

14. Du Plessis G. An existential perspective on addiction treatment: a logic-based therapy case study. International Journal of Philosophical Practice. 2019; 5(1):48-60. [DOI:10.2139/ssrn.3350606]

15. Kang KA, Kim SJ, Song MK, Kim MJ. Effects of logotherapy on life respect, meaning of life, and depression of older schoolage children. Journal of Korean Academy of Nursing. 2013; 43(1):91-101. [DOI:10.4040/jkan.2013.43.1.91] [PMID]

16. van Deurzen E, Tantam D. Creating the world congress for existential therapy. Existential Psychotherapy. 2016; 2(2):145-56. [DOI:10.1007/978-3-319-31086-2_11]

17. DeVito EE, Carroll KM, Babuscio T, Nich C, Sofuoglu M. Randomized placebo-controlled trial of galantamine in individuals with cocaine use disorder. Journal of Substance Abuse Treatment. 2019; 107(1):29-37. [DOI:10.1016/j.jsat. 2019.08.009] [PMID] [PMCID]

18. van Emmerik-van Oortmerssen K, Vedel E, Kramer FJ, Blankers M, Dekker JJ, van den Brink W, et al. Integrated cognitive behavioral therapy for ADHD in adult substance use disorder patients: results of a randomized clinical trial. Drug and Alcohol Dependence. 2019; 197(1):28-36. [DOI:10.1016/j.drugalcdep.2018.12.023] [PMID]

19. Delgadillo J, Gore S, Ali S, Ekers D, Gilbody S, Gilchrist G, et al. Feasibility randomized controlled trial of cognitive and behavioral interventions for depression symptoms in patients accessing drug and alcohol treatment. Journal of Substance Abuse Treatment. 2015; 55(1):6-14. [DOI:10.1016/j.jsat. 2015.02.008] [PMID]

20. Furukawa TA, Maruo K, Noma H, Tanaka S, Imai H,
Shinohara K, et al. Initial severity of major depression and efficacy of new generation antidepressants: individual participant data meta-analysis. Acta Psychiatrica Scandinavica. 2018; 137(6):450-8. [DOI:10.1111/acps.12886] [PMID]

21. Milosevic I, Chudzik SM, Boyd S, McCabe RE. Evaluation of an integrated group cognitive-behavioral treatment for comorbid mood, anxiety, and substance use disorders: a pilot study. Journal of Anxiety Disorders. 2017; 46(1):85100. [DOI:10.1016/j.janxdis.2016.08.002] [PMID]

22. Zhabenko O, Zhabenko N, Conroy DA, Chaban O, Oliinyk A, Frankova I, et al. An open uncontrolled pilot trial of online cognitive-behavioral therapy for insomnia for Ukrainian alcohol-dependent patients. Innovations in the Treatment of Substance Addiction. 2016; 2(1):165-81. [DOI:10.1007/978-3-319-43172-7_10]

23. Kiluk BD, Nich C, Babuscio T, Carroll KM. Quality versus quantity: acquisition of coping skills following computerized cognitive-behavioral therapy for substance use disorders. Addiction. 2010; 105(12):2120-7. [DOI:10.1111/j.13600443.2010.03076.x] [PMID] [PMCID]

24. Bador K, Kerekes N. Evaluation of an integrated intensive cognitive behavioral therapy treatment within addiction care. The Journal of Behavioral Health Services \& Research. 2020; 47(1):102-12. [DOI:10.1007/s11414-019-09657-5] [PMID] [PMCID]

25. Gür F, Gür GC, Okanlı A. The effect of the cognitivebehavioral model-based psychoeducation and exercise intervention on quality of life in alcohol use disorder. Archives of Psychiatric Nursing. 2017; 31(6):541-8. [DOI:10.1016/j.apnu.2017.07.005] [PMID]

26. Beck AT, Steer RA, Carbin MG. Psychometric properties of the beck depression inventory: twenty-five years of evaluation. Clinical Psychology Review. 1988; 8(1):77-100. [DOI:10.1016/0272-7358(88)90050-5]

27. Maroufizadeh S, Ghaheri A, Samani RO, Ezabadi Z. Psychometric properties of the satisfaction with life scale (SWLS) in Iranian infertile women. International Journal of Reproductive Biomedicine. 2016; 14(1):57-62. [PMID] [PMCID]

28. Kajbaf MB, Ghasemiannejad Jahromi A, Ahmadi Forushani $\mathrm{SH}$. The effectiveness of spiritual and existential group therapy on the rates of depression, death anxiety and afterlife belief among students: a study based on the reports of people with death experience. Knowledge \& Research in Applied Psychology. 2016; 16(4):4-13.

29. Khaledian M, Kamar Zarin H, Jalalian A. The effectiveness of group cognitive behavior therapy on reduction of addicts' depression. Research on Addiction. 2014; 8(29):77-88. 